\title{
The Role of Apoptosis in Thyroid Autoimmunity
}

\author{
Su He Wang and James R. Baker, Jr.
}

There is increasing evidence showing that apoptosis plays a role in the development of the autoimmune thyroid diseases-Hashimoto's (lymphocytic) thyroiditis (HT) and Graves' disease (GD). The immune pathogenesis of HT and GD is not yet fully understood, but evidence points toward several steps. A defect in $\mathrm{CD} 4{ }^{+} \mathrm{CD} 25^{+} \mathrm{T}$ regulatory cells breaks the immunological tolerance of the host and induces an abnormal production of cytokines, which facilitates the initiation of apoptosis. Though apoptosis appears to play a role in the pathogenesis of both HT and GD, the mechanisms that mediate these processes appear different. The induction of apoptosis in HT results in the destruction of thyrocytes, while apoptosis in the GD leads to damage of thyroid-infiltrating lymphocytes. The differences in the apoptotic mechanisms produce two very different forms of thyroid autoimmune responses, eventually developing into HT and GD, respectively.

\section{Introduction}

A UTOIMMUNE THYROID DISEASE (AITD) Is the most common organ-specific autoimmune disorder. The etiology of AITD is still unclear, but the susceptibility to it is determined by a combination of genetic and environmental factors. The pathogenesis of AITD is known to be associated with autoimmune processes against various constituents of thyroid tissues, including cell membranes, receptors, and enzymes. AITD affects $1-2 \%$ of the population, with a 5 - to 10 -fold increase among women. AITD encompasses two entities: autoimmune thyroiditis and autoimmune hyperthyroidism. The former is represented by Hashimoto's (lymphocytic) thyroiditis (HT) and the latter by Graves' disease (GD).

No unique immune response to thyroid autoantigens has been identified that is absolutely correlated with the expression of clinical AITD (1). The triggering event for AITD is not known, but the pathogenesis of AITD appears to be multifactorial. Genetic background and environmental and endogenous factors are thought to play important roles in determining the activation threshold of immune cells or the efficacy of the immunoregulatory pathways. However, the procedures responsible for this process are just being clarified.

Apoptosis-or programmed cell death-is an evolutionarily preserved mechanism of the self-elimination of damaged cells. It is important throughout the life of an organism, playing a role in every process from development to aging. The apoptotic cascade can be triggered either through a death receptor-mediated pathway or through mitochondrialmediated changes. During the past few years, increasing evidence has suggested that receptor-mediated apoptosis plays a key role in the process of AITD development, the common feature of which is the survival of specific, unchecked selfreactive lymphocytes against the thyroid (2-4). While several of our prior reviews have focused on the regulation of apoptosis in the thyroid, we are focusing this discussion on the role of apoptosis in immune pathogenesis of these diseases. The homeostasis of the self-reactive lymphocytes is decided by the balance between antiapoptotic and proapoptotic molecules. The loss of this balance may lead to the self-immune system's attack on the thyroid, during which organ-specific lymphocytes can convey death signals to thyroid follicular cells. This initiates damage to the thyroid, leading to hypothyroidism in HT or to hyperthyroidism in GD. In this review, we will discuss the role of apoptosis in the pathogenesis of HT and GD.

\section{Hashimoto's Thyroiditis}

HT is characterized by inflammatory cell infiltration of the thyroid parenchyma, causing a dense accumulation of lymphocytes, plasma cells, and macrophages with germinal center formation and thyroid enlargement (5). The central feature of HT is the presence of autoantibodies to thyroglobulin and to thyroid peroxidase. The etiology of HT is not known, but it is believed to involve an interplay among genetic, environmental, and endogenous factors. The relative contribution of each is not clearly defined and may vary from patient to patient.

There are several steps hypothesized to play a role in the immune pathogenesis of HT. Initially, the immune system in an individual susceptible to HT is altered by changes in

Department of Internal Medicine, University of Michigan Medical School, Ann Arbor, Michigan. 
environmental factors and/or endogenous elements. Such alterations in the immune system appear to result in defects in the Cytotoxic T-lymphocyte-associated protein 4 (CTLA-4), $\mathrm{CD}^{+}{ }^{+} \mathrm{CD} 25^{+} \mathrm{T}$ regulatory cells (Treg cells) (6-8), which normally represent an important mechanism for the maintenance of self-tolerance. Supporting this concept, studies have shown that removal of $\mathrm{CD} 4{ }^{+} \mathrm{CD} 25^{+}$Treg cells from mice that do not develop autoimmunity can result in autoimmune thyroiditis (6). Furthermore, adoptive transfer of Treg cells is able to prevent experimental autoimmune thyroiditis (7-9). The reason that there are fewer and/or dysfunctional Treg cells in autoimmune pathogenesis remains unclear. However, in several autoimmune disease models, a mutation of the forkhead box protein P3 (Foxp3) gene, which is a characteristic and functional marker of Treg cells, has been observed (10). A specific genetic defect may also be responsible for causing an autoimmune response by inducing autoreactive $\mathrm{T}$ cells to break self-tolerance. This type of genetic defect has also been reported to be associated with a decreased number of Treg cells (11). Nevertheless, even in normal hosts, the depletion of Treg cells can result in defects in the immune surveillance system, leading to an "unchecked" status with a decrease or defect in the inhibitory functions of $\mathrm{CD}^{+}$and $\mathrm{CD} 8^{+} \mathrm{T}$ cells $(6,12,13)$. In such a situation, the host loses immunological tolerance and eventually develops autoimmune diseases $(14,15)$.

Despite intensive efforts during the past several years, the molecular mechanisms by which Treg cells exert their immunosuppressive function still remain undiscovered. A change in the thyroid microenvironment is believed to follow the defect in Treg cells. One of the important functions of Treg cells is to inhibit $\mathrm{T}$ helper 1 (Th1)-driven autoimmune and inflammatory responses $(16,17)$. The defect in Treg cells thus removes its inhibition on the function of Th1 cells, resulting in the overproduction of Th1 cytokines, including interleukin 1 beta (IL-1 $\beta$ ), interferon gamma (IFN $\gamma$ ), and tumor necrosisrelated alpha $(\mathrm{TNF} \alpha)$. The Th1 cytokine production pattern occurs not only in intrathyroidal but also in peripheral CD4 $4^{+}$ and $\mathrm{CD}^{+} \mathrm{T}$ lymphocytes in HT patients (18). These cytokines are able to trigger a number of events, including apoptosis in thyroid cells $(19,20)$.

Increasing evidence has emerged to support the theory that the destruction of thyroid follicles occurs by the apoptotic mechanisms $(19,21)$. Thyroid cells are known to express apoptotic ligands and receptors, such as TNF, Fas, and Tumor necrosis-related apoptosis-inducing ligand (TRAIL) (1). Under normal physiologic conditions, the apoptotic molecules remain inactivated or will lack a trigger. Therefore, the thyrocytes are normally safeguarded against apoptosis through the physiological inhibition of their apoptotic pathways. Though Fas is known to express constitutively on the thyrocytes, it does not normally cause apoptosis-even in the presence of excess Fasinducing ligands. However, the expression of FasL on thyroidinfiltrating lymphocytes is usually increased, which leads to apoptosis of these invading lymphocytes (22). In order to maintain this finely tuned Fas-FasL pathway, apoptotic signaling would be inhibited in thyrocytes but activated in infiltrating lymphocytes. The molecules that are responsible for apoptosis regulation in thyrocytes remain unknown. However, the inhibition can be reversed by the administration of cycloheximide, an inhibitor of protein translation, suggesting it involves a labile protein (although there may be more than one inhibitor or labile protein involved) (23). Quite interestingly, the activation of the Fas-FasL pathway normally inhibited in thyrocytes is induced by certain combinations of proinflammatory cytokines, such as IL- $1 \beta, \operatorname{IFN} \gamma$, and $\operatorname{TNF} \alpha$, but not by any one single cytokine $(1,20,21,24)$. The apoptosis activation has been associated with an increase of caspases 7,8 , and 10, as well as the concentration of Bid and Bak. A decrease of p44/42 mitogen-activated protein kinase activity is concomitantly observed $(19,20,24)$. Therefore, it appears that the apoptotic pathway initiated by the Fas-FasL interaction may be further amplified by the proapoptotic molecule Bid, leading to the release of Bak from the mitochondria and the activation of caspases. These observations suggest that apoptosis of thyrocytes in HT is both a cell death receptordependent and a mitochondrion-dependent event. Unfortunately, apoptotic cell clearance does not appear to produce an anti-inflammatory situation in autoimmune diseases; instead, the impaired apoptotic cells and secondary necrotic cells induce a proinflammatory state (25), which may provide sufficient levels of self-antigens to intensify a dysregulated autoimmune response. Therefore, the apoptosis of thyrocytes in HT may be both the result of defective immunological tolerance and a positive feedback loop to exacerbate thyroid inflammation.

While defects in the $\mathrm{CD} 4{ }^{+} \mathrm{CD} 25^{+}$Treg result in the activation of Th1 cells and the overproduction of Th1 cytokines, they may also promote an autoimmune response by the downregulation of a number of molecules that are known to have immunosuppressive effects. These molecules include CD25, IL-2, CTLA-4, IL-10, glucocorticoid-induced tumor necrosis factor receptor (GITR), lymphocyte activation gene-3 (LAG-3), Foxp3, and transforming growth factor-beta (TGF $\beta$ ). Although none of these molecules can fit into a single model of immune regulation, it is possible that the reduction of several of these molecules may enhance the activity of B cells, which produce autoantibodies, the diagnostic feature of HT $(26,27)$.

It is not known how the thyroid microenvironment leads to the defect in $\mathrm{CD} 4{ }^{+} \mathrm{CD} 25^{+}$Treg cells in the thyroid. The Treg cells appear to be abundant in inflamed thyroid tissues. However, they are apparently dysfunctional in most cases and are unable to downmodulate the autoimmune response (28). The expression of Fas in $\mathrm{CD} 4{ }^{+} \mathrm{CD} 25^{+}$Treg cells is greater in patients with severe HT than in those with mild HT (29). This phenomenon is consistent with the observation that the proportion of apoptotic cells among $\mathrm{CD} 44^{+} \mathrm{CD} 25^{+}$Treg cells is higher than that among $\mathrm{CD} 4{ }^{+} \mathrm{CD} 25^{-}$Treg cells in the thyroid of a patient with AITD. In addition to the high expression of Fas in $\mathrm{CD}^{+} \mathrm{CD} 25^{+}$Treg cells in the thyroid, these cells also strongly express other proapoptotic genes, such as TRAIL and $\mathrm{TNF} \alpha$, and weakly express antiapoptotic genes, such as Bcl-2. This appears to make the Treg cells uniquely susceptible to Fas-mediated apoptosis $(30,31)$. Therefore, it has been proposed that the defect or reduction of $\mathrm{CD} 4^{+} \mathrm{CD} 25^{+}$Treg cells results from the increased apoptosis of $\mathrm{CD} 4{ }^{+} \mathrm{CD} 25^{+}$Treg cells in an inflamed thyroid gland (12). In addition, our recent data also suggest that TRAIL, a death receptor ligand, can enhance $\mathrm{CD} 4^{+} \mathrm{CD} 25^{+}$Treg cell proliferation in vitro (32). This may involve inhibition of the development of experimental autoimmune thyroiditis by TRAIL. Further study is underway to address it. 


\section{Graves' Disease}

GD accounts for most cases of hyperthyroidism. The identification in the serum of patients with GD of an abnormal thyroid stimulator protein, originally named long-acting thyroid stimulator (LATS), that was subsequently identified as an autoantibody against thyroid follicular cell thyrotropin (TSH) receptors first identified this disorder as an autoimmune disease (5). Similar to HT, GD is characterized by lymphocytic infiltration of the thyroid gland although much less severe in nature and not associated with disruption of the normal thyroid architecture. It is believed that $\mathrm{T}$ cells and $\mathrm{B}$ cells accumulate in the thyroid gland as a result of various factors, such as viral/bacterial infection, stress, sex hormones, and genetic abnormality. Cytokines and other cellular molecules released during these interactions can upregulate the expression of major histocompatibility complex (MHC) class I and class II molecules on the surface of the thyroid cells (33). These cells may then become adequate antigen-presenting cells and present a display of TSH receptor peptides. Alternatively, infection might produce mimic molecules or alter host cell components such that they could be attacked by the immune system $(34,35)$.

An immune response is initiated in GD when T-cell receptors recognize foreign peptides or self-peptide fragments bound to human leukocyte antigen (HLA) molecules encoded by MHC genes $(33,35)$. Class II antigens are usually expressed only on antigen-presenting cells, such as B cells and macrophages, and not on epithelial cells, such as thyrocytes. Several HLA molecules encoded by class II gene region are known to be associated with GD. Abnormal or aberrant expression of these antigens on thyrocytes and lymphocytes may play a key role in the development of GD $(33,35)$.

Analysis of the phenotypic profile of intrathyroidal $\mathrm{T}$ lymphocytes in GD reveals a CD4 ${ }^{+} \mathrm{T}$-cell predominance, but with some of these T cells expressing CD8 (28). CD4 ${ }^{+} \mathrm{T}$ cells may be capable of helping local B cells to produce antibodies. Recent studies have indicated that some of the $\mathrm{CD} 4^{+} \mathrm{T}$ cells in the thyroids of GD patients are CD $4^{+} \mathrm{CD} 25^{+}$Treg cells $(29,36)$. The role of the $\mathrm{CD} 4{ }^{+} \mathrm{CD} 25^{+}$Treg cells in GD is not quite clear. However, there is evidence that shows that the inhibition of Treg cells may induce Th2-like cells (37). The cytokines generated by Th2 cells are IL-4, IL-5, and IL-10, the levels of which are increased in GD $(38,39)$. Similarly to HT, the number of Treg cells in GD may also be decreased-probably via the Fasmediated apoptotic pathway (36). Therefore, it would appear that the reduction of Treg cells could favor Th2 cytokine production in GD.

Th2 cytokine predominance promotes humoral immunity instead of cellular immunity, enhancing autoantibody production by the B lymphocytes. Interestingly, increased concentrations of Immunoglobulin G (IgG) due to the activity of Th2 cells or Th2 cytokines may downregulate the expression of Fas but upregulate the antiapoptotic molecules, such as Bcl-2, Bcl-xL, and cFLIP in thyrocytes (2,39-42). This could lead to the protection of thyrocytes from apoptosis $(2,40-43)$. In addition, soluble Fas may also play a role in the inhibition of the Fas-FasL system in patients with GD because the serum concentration of sFas is increased in patients with GD $(44,45)$. The overexpression of antiapoptosis molecules such as Bcl-2 may render the thyrocytes of GD resistant to Fas-

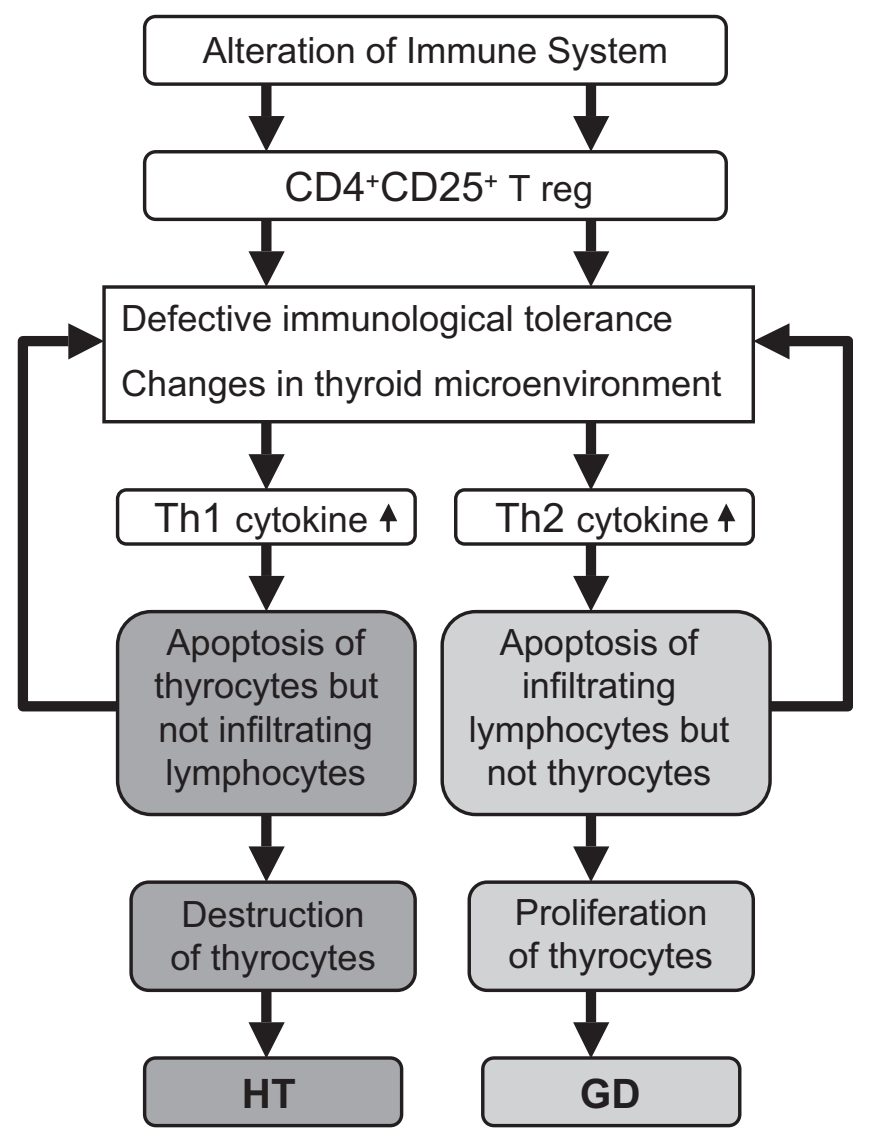

FIG. 1. Pathogenesis of Hashimoto's (lymphocytic) thyroiditis (HT) and Graves' disease (GD).

FasL-mediated cell death (46). However, this resistance is not likely to be present in thyroid-infiltrating lymphocytes, where the expression of proapoptotic Bax and Bak proteins is apparent (47). Therefore, the infiltrating lymphocytes in GD thyroids are susceptible to apoptosis, but the thyrocytes may escape apoptosis via the overexpression of antiapoptotic molecules $(45,46)$.

Therefore, it appears likely that the thyroid microenvironment in GD is regulated in a manner that is almost completely opposite to that of HT (Fig. 1). In GD, the immune response promotes thyrocyte survival and hypertrophy and may lead to lymphocyte apoptosis.

\section{Conclusion}

Strong evidence has supported the theory that apoptosis plays an important role in the development of AITD (Fig. 1). HT and GD are two major forms of AITD. Apoptosis of thyrocytes is initiated by Th1 cytokines in HT, which overcome the built-in apoptosis inhibitory mechanisms of the thyrocytes. In GD, the production of Th2 cytokines dominates in the thyroid, and thyrocytes are protected from apoptosis via overexpression of antiapoptotic molecules such as Bcl-2. The infiltrating lymphocytes appear unable to invoke these protective mechanisms and thus undergo apoptosis. A defect in $\mathrm{CD} 4{ }^{+} \mathrm{CD} 25^{+}$Treg cells is associated with both HT and GD and is believed to play a critical role in determining the 
production of Th1 and Th2 cytokines. It remains unknown why the defect in $\mathrm{CD} 4^{+} \mathrm{CD} 25^{+}$Treg cells favors Th1 cytokine production in HT, whereas it prefers Th2 cytokine production in GD. This warrants future investigation.

\section{References}

1. Arscott PL, Baker JR Jr. 1998 Apoptosis and thyroiditis. Clin Immunol Immunopathol 87:207-217.

2. Stassi G, Di Liberto D, Todaro M, Zeuner A, Ricci-Vitiani L, Stoppacciaro A, Ruco L, Farina F, Zummo G, De Maria R 2000 Control of target cell survival in thyroid autoimmunity by $\mathrm{T}$ helper cytokines via regulation of apoptotic proteins. Nat Immunol 1:483-488.

3. Stassi G, De Maria R 2002 Autoimmune thyroid disease: new models of cell death in autoimmunity. Nat Rev Immunol 2:195-204.

4. Fountoulakis S, Tsatsoulis A 2004 On the pathogenesis of autoimmune thyroid disease: a unifying hypothesis. Clin Endocrinol (Oxf) 60:397-409.

5. Ban Y, Tomer Y 2003 The contribution of immune regulatory and thyroid specific genes to the etiology of Graves' and Hashimoto's diseases. Autoimmunity 36:367-379.

6. Wei WZ, Jacob JB, Zielinski JF, Flynn JC, Shim KD, Alsharabi G, Giraldo AA, Kong YC 2005 Concurrent induction of antitumor immunity and autoimmune thyroiditis in CD4+ CD25+ regulatory T cell-depleted mice. Cancer Res 65:8471-8478.

7. Verginis P, Li HS, Carayanniotis G 2005 Tolerogenic semimature dendritic cells suppress experimental autoimmune thyroiditis by activation of thyroglobulin-specific CD4+ CD25+ T cells. J Immunol 174:7433-7439.

8. Gangi E, Vasu C, Cheatem D, Prabhakar BS 2005 IL-10producing $\mathrm{CD} 4+\mathrm{CD} 25+$ regulatory $\mathrm{T}$ cells play a critical role in granulocyte-macrophage colony-stimulating factorinduced suppression of experimental autoimmune thyroiditis. J Immunol 174:7006-7013.

9. Flynn JC, Meroueh C, Snower DP, David CS, Kong YM 2007 Depletion of $\mathrm{CD} 4+\mathrm{CD} 25+$ regulatory $\mathrm{T}$ cells exacerbates sodium iodide-induced experimental autoimmune thyroiditis in human leukocyte antigen DR3 (DRB1*0301) transgenic class II-knock-out non-obese diabetic mice. Clin Exp Immunol 147:547-554.

10. $\overline{\text { Hori S }}$, Nomura T, Sakaguchi S 2003 Control of regulatory T cell development by the transcription factor Foxp3. Science 299:1057-1061.

11. Chen Y, Cuda C, Morel L 2005 Genetic determination of T cell help in loss of tolerance to nuclear antigens. I Immunol 174:7692-7702.

12. Taams LS, Smith J, Rustin MH, Salmon M, Poulter LW, Akbar AN 2001 Human anergic/suppressive CD4(+)CD25(+) T cells: a highly differentiated and apoptosis-prone population. Eur J Immunol 31:1122-1131.

13. Kawakami A, Matsuoka N, Tsuboi M, Koji T, Urayama S, Sera N, Hida A, Usa T, Kimura H, Yokoyama N, Nakashima T, Ishikawa N, Ito K, Kawabe Y, Eguchi K 2000 CD4+ T cellmediated cytotoxicity toward thyrocytes: the importance of Fas/Fas ligand interaction inducing apoptosis of thyrocytes and the inhibitory effect of thyroid-stimulating hormone. Lab Invest 80:471-484.

14. Lan RY, Ansari AA, Lian ZX, Gershwin ME 2005 Regulatory $T$ cells: development, function and role in autoimmunity. Autoimmun Rev 4:351-363.

15. Torgerson TR 2006 Regulatory T cells in human autoimmune diseases. Springer Semin Immunopathol 28:63-76.
16. Baecher-Allan C, Hafler DA 2006 Human regulatory T cells and their role in autoimmune disease. Immunol Rev 212:203216.

17. Daniel C, Sartory N, Zahn N, Geisslinger G, Radeke HH, Stein JM 2007 FTY720 ameliorates Th1-mediated colitis in mice by directly affecting the functional activity of $\mathrm{CD} 4{ }^{+} \mathrm{CD} 25^{+}$regulatory T cells. J Immunol 178:2458-2468.

18. Mazziotti G, Sorvillo F, Naclerio C, Farzati A, Cioffi M, Perna R, Valentini G, Farzati B, Amato G, Carella C 2003 Type- 1 response in peripheral CD4+ and CD8+ T cells from patients with Hashimoto's thyroiditis. Eur J Endocrinol 148:383-388.

19. Wang SH, Mezosi E, Wolf JM, Cao Z, Utsugi S, Gauger PG, Doherty GM, Baker JR, Jr 2004 IFNgamma sensitization to TRAIL-induced apoptosis in human thyroid carcinoma cells by upregulating Bak expression. Oncogene 23:928-935.

20. Mezosi E, Wang SH, Utsugi S, Bajnok L, Bretz JD, Gauger PG, Thompson NW, Baker JR, Jr 2004 Interleukin-1beta and tumor necrosis factor (TNF)-alpha sensitize human thyroid epithelial cells to TNF-related apoptosis-inducing ligand-induced apoptosis through increases in procaspase-7 and bid, and the down-regulation of p44/42 mitogen-activated protein kinase activity. J Clin Endocrinol Metab 89:250-257.

21. Baker JR, Jr 1999 Dying (apoptosing?) for a consensus on the Fas death pathway in the thyroid. J Clin Endocrinol Metab 84:2593-2595.

22. Batteux F, Tourneur L, Trebeden H, Charreire J, Chiocchia G 1999 Gene therapy of experimental autoimmune thyroiditis by in vivo administration of plasmid DNA coding Fas ligand. J Immunol 162:603-608.

23. Arscott PL, Knapp J, Rymaszewski M, Bartron JL, Bretz JD, Thompson NW, Baker JR, Jr 1997 Fas (APO-1, CD95)mediated apoptosis in thyroid cells is regulated by a labile protein inhibitor. Endocrinology 138:5019-5027.

24. Mezosi E, Wang SH, Utsugi S, Bajnok L, Bretz JD, Gauger PG, Thompson NW, Baker JR, Jr 2005 Induction and regulation of Fas-mediated apoptosis in human thyroid epithelial cells. Mol Endocrinol 19:804-811.

25. Ren Y, Tang J, Mok MY, Chan AW, Wu A, Lau CS 2003 Increased apoptotic neutrophils and macrophages and impaired macrophage phagocytic clearance of apoptotic neutrophils in systemic lupus erythematosus. Arthritis Rheum 48: 2888-2897.

26. Baker JR, Jr 1988 Immunologic aspects of endocrine diseases. Ann Intern Med 108:26-30.

27. Bonger U, Finke R, Hegedus L, Hanseb JM, Schleusener H 1993 Cytotoxicity and antithyroid peroxidase antibodies in patients with autoimmune thyroiditis. In: Nagataki S, Mori T, Torizuka K (eds) 80 Years of Hashimoto Disease. Elsevier Science Publishers B.V., Amsterdam, Netherlands, pp 383388.

28. Weetman AP, McGregor AM 1994 Autoimmune thyroid disease: further developments in our understanding. Endocr Rev 15:788-830.

29. Marazuela M, Garcia-Lopez MA, Figueroa-Vega N, de la Fuente H, Alvarado-Sanchez B, Monsivais-Urenda A, Sanchez-Madrid F, Gonzalez-Amaro R 2006 Regulatory T cells in human autoimmune thyroid disease. J Clin Endocrinol Metab 91:3639-3646.

30. Maruoka $H$, Watanabe $M$, Matsuzuka F, Takimoto $T$, Miyauchi A, Iwatani Y 2004 Increased intensities of fas expression on peripheral T-cell subsets in severe autoimmune thyroid disease. Thyroid 14:417-423. 
31. Kasprowicz DJ, Droin N, Soper DM, Ramsdell F, Green DR, Ziegler SF 2005 Dynamic regulation of FoxP3 expression controls the balance between CD4 $+\mathrm{T}$ cell activation and cell death. Eur J Immunol 35:3424-3432.

32. Wang SH, Chen GH, Van Antwerp M, Baker Jr. JR 2006 Enhancement of the regulatory $\mathrm{T}$ cell proliferation by TRAIL. Thyroid 16:891. (Abstract).

33. Shimojo N, Arima T, Yamaguchi K, Kikuoka S, Kohn LD, Kohno Y 2003 A novel mouse model of Graves' disease: implications for a role of aberrant MHC class II expression in its pathogenesis. Int Rev Immunol 19:619-631.

34. Heyma P, Harrison LC, Robins-Browne R 1986 Thyrotrophin (TSH) binding sites on Yersinia enterocolitica recognized by immunoglobulins from humans with Graves' disease. Clin Exp Immunol 64:249-254.

35. Kohn LD, Napolitano G, Singer DS, Molteni M, Scorza R, Shimojo N, Kohno Y, Mozes E, Nakazato M, Ulianich L, Chung HK, Matoba H, Saunier B, Suzuki K, Schuppert F, Saji M 2000 Graves' disease: a host defense mechanism gone awry. Int Rev Immunol 19:633-664.

36. Nakano A, Watanabe M, Iida T, Kuroda S, Matsuzuka F, Miyauchi A, Iwatani Y 2007 Apoptosis-induced decrease of intrathyroidal $\mathrm{CD} 4(+) \mathrm{CD} 25(+)$ regulatory $\mathrm{T}$ cells in autoimmune thyroid diseases. Thyroid 17:25-31.

37. Veldman C, Pahl A, Beissert S, Hansen W, Buer J, Dieckmann D, Schuler G, Hertl M 2006 Inhibition of the transcription factor Foxp3 converts desmoglein 3-specific type 1 regulatory $\mathrm{T}$ cells into Th2-like cells. J Immunol 176:32153222.

38. Phenekos C, Vryonidou A, Gritzapis AD, Baxevanis CN, Goula M, Papamichail M 2004 Th1 and Th2 serum cytokine profiles characterize patients with Hashimoto's thyroiditis (Th1) and Graves' disease (Th2). Neuroimmunomodulation 11:209-213.

39. Kocjan T, Wraber B, Repnik U, Hojker S 2000 Changes in Th1/Th2 cytokine balance in Graves' disease. Pflugers Arch 440 Suppl 5:R94-R95.

40. Kawakami A, Eguchi K, Matsuoka N, Tsuboi M, Urayama S, Kawabe Y, Tahara K, Ishikawa N, Ito K, Nagataki S 1997 Modulation of Fas-mediated apoptosis of human thyroid epithelial cells by IgG from patients with Graves' disease
(GD) and idiopathic myxedema. Clin Exp Immunol 110:434439.

41. Kawakami A, Matsuoka N, Tsuboi M, Koji T, Urayama S, Sera N, Hida A, Usa T, Kimura H, Yokoyama N, Nakashima T, Ishikawa N, Ito K, Kawabe Y, Eguchi K 2000 CD4+ T cellmediated cytotoxicity toward thyrocytes: the importance of Fas/Fas ligand interaction inducing apoptosis of thyrocytes and the inhibitory effect of thyroid-stimulating hormone. Lab Invest 80:471-484.

42. Nagayama $Y$, Mizuguchi H, Hayakawa T, Niwa M, McLachlan SM, Rapoport B 2003 Prevention of autoantibodymediated Graves'-like hyperthyroidism in mice with IL-4, a Th2 cytokine. J Immunol 170:3522-3527.

43. Dogan RN, Vasu C, Holterman MJ, Prabhakar BS 2003 Absence of IL-4, and not suppression of the Th2 response, prevents development of experimental autoimmune Graves' disease. J Immunol 170:2195-2204.

44. Feldkamp J, Pascher E, Schott M, Goretzki P, Seissler J, Scherbaum WA 2001 Soluble Fas is increased in hyperthyroidism independent of the underlying thyroid disease. J I lin Endocrinol Metab 86:4250-4253.

45. Hiromatsu Y, Bednarczuk T, Soyejima E, Miyake I, Yang D, Fukazawa H, Nonaka K 1999 Increased serum soluble Fas in patients with Graves' disease. Thyroid 9:341-345.

46. Hiromatsu Y, Hoshino T, Yagita H, Koga M, Sakisaka S, Honda J, Yang D, Kayagaki N, Okumura K, Nonaka K 1999 Functional Fas ligand expression in thyrocytes from patients with Graves' disease. J Clin Endocrinol Metab 84: 2896-2902.

47. Hiromatsu Y, Kaku H, Mukai T, Miyake I, Fukutani T, Koga M, Shoji S, Toda S, Koike N 2004 Immunohistochemical analysis of bcl-2, Bax and Bak expression in thyroid glands from patients with Graves' disease. Endocr J 51:399-405.

Address reprint requests to: Su He Wang

Department of Internal Medicine University of Michigan Medical School Ann Arbor, MI 48190

E-mail: shidasui@umich.edu 

This article has been cited by:

1. J. Jiskra, M. Antošová, Z. Límanová, Z. Telička, Z. Lacinová. 2009. The relationship between thyroid function, serum monokine induced by interferon gamma and soluble interleukin-2 receptor in thyroid autoimmune diseases. Clinical \& Experimental Immunology 156:2, 211-216. [CrossRef]

2. Rachel Desailloud, Famara Sané , Delphine Caloone, Didier Hober . 2009. Persistent Infection of a Carcinoma Thyroid Cell Line with Coxsackievirus BPersistent Infection of a Carcinoma Thyroid Cell Line with Coxsackievirus B. Thyroid 19:4, 369-374. [Abstract] [PDF] [PDF Plus] [Supplementary material] 